\title{
A cohort study of mortality and cancer incidence in ethylene oxide production workers
}

\author{
C. HOGSTEDT 1 , O. ROHLEN ${ }^{2}$, B. S. BERNDTSSON ${ }^{2}$, O. AXELSON ${ }^{3}$, \\ AND L. EHRENBERG ${ }^{4}$ \\ From the ${ }^{1}$ Department of Occupational Medicine, Regional Hospital, S-701 85 Örebro, ${ }^{2}$ Berol Kemi AB, \\ Stenungsund, ${ }^{3}$ Department of Occupational Medicine, University Hospital, Linköping, and the \\ ${ }^{4}$ Wallenberg Laboratory, Stockholm University, Stockholm, Sweden
}

\begin{abstract}
Ethylene oxide, important as an intermediate product in the chemical industry and for sterilising hospital equipment, is mutagenic in several organisms; carcinogenicity has been suspected although this has not been supported by clinical data. Ethylene oxide has been produced by a Swedish company since the beginning of the 1940s. This paper describes a cohort study of the mortality and the cancer incidence among full-time exposed workers in ethylene oxide production, a group of maintenance workers with intermittent exposure and a group of unexposed controls. Investigation of the production processes in the building at different times has shown that workers were exposed to ethylene dichloride, ethylene chlorohydrin, ethylene, and small amounts of bis(2-chloroethyl) ether as well as to ethylene oxide and traces of other chemicals. The full-time exposed cohort shows a considerable excess mortality deriving mainly from increased mortality from tumours and also from diseases of the circulatory system. The cancer incidence study, including living persons with malignancies, showed a significant excess in the full-time cohort. Of the 16 patients with tumours in the two more exposed cohorts there were three cases of leukaemia, six of tumours in the alimentary tract and four of urogenital malignancy. The excess mortality and cancer incidence cannot be attributed to any particular chemical in the production process, but ethylene oxide and ethylene dichloride are the prime suspects.
\end{abstract}

Ethylene oxide has been produced commercially since the 1920s and is an important intermediate product in the chemical industry, for example in the production of ethylene glycol and some surfaceactive agents. It has been used for sterilising hospital equipment and food.

The literature on the human toxicology of ethylene oxide deals mostly with respiratory and skin irritation (Hine and Rowe, 1963). However, ethylene oxide is a strong mutagen in several organisms, such as Drosophila (Rapoport, 1948). Increased chromosomal aberrations have been observed in human lymphocytes from accidentally exposed subjects (Ehrenberg and Hällström, 1967). Those findings led to early warnings that ethylene oxide

Received for publication 6 December 1978 Accepted for publication 26 February 1979 might be a carcinogen (Ehrenberg and Gustafsson 1970) and further warnings have followed (National Institute for Occupational Safety and Health, 1977; Environmental Protection Agency, 1978). Two small animal studies (Walpole, 1957; van Duuren et al., 1965) were negative but have been regarded as inconclusive (International Agency for Research on Cancer, 1976). Joyner (1964) made a cross-sectional health examination of 37 ethylene oxide operators and 8 previous operators, all of whom had worked in ethylene oxide production for a period of more than 10 years. The group was found to have a somewhat better medical history than the controls. Malignancies, which could hardly be expected among active workers, were not found. Recently, three cases of leukaemia were reported in a small group of ethylene oxide exposed personnel in Sweden with a calculated mean exposure of $20 \pm 10$ 
ppm ethylene oxide for 4-10 years (Hogstedt et al., 1979). The expected number was $0 \cdot 2$ cases of leukaemia.

Ethylene oxide has been produced by a Swedish company since the beginning of the 1940s. A haematological investigation was carried out in that company in 1960-61 by Ehrenberg and Hällström (1967) on 243 men, 37 of whom were permanently working in the ethylene oxide manufacture area (group D); 54 had previously worked in this area (group C); 86 men were intermittently working in the ethylene oxide area (maintenance workers; group B) and the remaining 66 men had never worked in ethylene oxide production (group A). There were no significant differences between the groups, but a subgroup of 28 individuals with high exposure showed decreased haemoglobin concentration and significant lymphocytosis $(\mathrm{P}<0.05)$.

It was thought likely that a follow-up study of these workers with regard to mortality and cancer incidence would provide some information on whether the exposure to chemicals in ethylene oxide industry had been hazardous, using the unexposed men as an internal control group.

\section{Material and methods}

All men who were included in the 1960-61 examination and who were exposed or employed for more than one year have been included in the present study and, for convenience, the previous exposure categories have also been used. The study included three subcohorts, comprising 89 full-time exposed men (originally referred to as group $C+D$ ) of whom only two men were exposed for less than one year), 86 intermittently exposed men (maintenance workers, group B) and 66 men who had never taken part in work involving exposure to ethylene oxide (group A).

The follow-up started in January 1961 and continued until the end of December 1977; this period is referred to as the study period. The expected numbers of deaths and malignancies were calculated by multiplying the person-years of observation within five-year age categories during the respective calendar years of the study period by the cause-, sex-, and age-specific national death rates for the whole of Sweden, as well as the cause-, age-, and sex-specific cancer incidence rates from the respective calendar years of the study period, and by summarising the fractional contributions over all the different subcohorts. However, at least ten years of induction-latency time was required from the beginning of the exposure until starting the observation of person-years under risk or of the deceased. Nobody was lost to follow-up in any of the cohorts. Death certificates for all the dead subjects have been checked with the National Central Bureau of Statistics and the officially determined underlying cause of death has been used. The Swedish Cancer Registry provided the diagnoses for the malignancies in dead or alive subjects.

\section{EXPOSURE}

The pattern of exposure in the chemical industry is often complex. In this industry ethylene oxide was produced according to the so-called chlorohydrin process and the personnel in the exposed groups worked not only in the production of ethylene oxide and related end-products, but also with other chemicals. Most of the production took place inside a building with air passing between the different departments where chlorinated products such as chloroform, chlorinated acetals, chloral and DDT were produced, as well as ethylene glycol, surfactants and cellulose ethers.

In the chlorohydrin process, which starts from ethylene (obtained by dehydrating ethyl alcohol), ethylene chlorohydrin is produced as an intermediate product. Ethylene dichloride and smaller amounts of bis (2-chloroethyl) ether are principal by-products. After a careful investigation of the production processes over the years back to the 40s, it is possible to suggest rough estimates of exposure levels to various compounds.

The composition of the vapour phase in the chlorohydrin towers can be calculated from production data. Taking into consideration contamination of the fresh air intake by waste vapours from the towers, plus occasional emission of vapours into the workroom, and by applying a dilution factor of 1000, the exposure during the period 1941-47 can be estimated as approximately $5 \mathrm{mg} / \mathrm{m}^{3}$ ethylene chlorohydrin, $100 \mathrm{mg} / \mathrm{m}^{3}$ ethylene dichloride, $0.05 \mathrm{mg} / \mathrm{m}^{3}$ bis (2-chloroethyl) ether and about $600 \mathrm{mg} / \mathrm{m}^{3}$ ethylene; however, it is possible that up to 1000 times those concentrations may have occurred momentarily. The work time in the chlorohydrin room has been estimated as slightly more than $1 \mathrm{~h}$ per shift.

In the distillation department during the same period there were occasional exposures to ethylene oxide up to the odour threshold $\left(1300 \mathrm{mg} / \mathrm{m}^{3}\right)$, when samples were taken, but the average exposure, in connection with ethylene oxide production and its use in ethylene glycol manufacture, was much lower and probably below $25 \mathrm{mg} / \mathrm{m}^{3}$.

During the 1950s and until 1963, exposure to chemicals other than ethylene oxide decreased because of production changes, while exposure to ethylene oxide increased with more production of compounds based on ethylene oxide, such as surfactants and cellulose ethers, and an average air 
Table 1 Observed and expected number of deaths from various causes during 1961-77 in three different cohorts, with or without relation to ethylene oxide production. At least one year of exposure and 10 years or more of induction-latency time were required

\begin{tabular}{|c|c|c|c|c|c|c|c|}
\hline \multirow[t]{2}{*}{ ICD no. } & \multirow[t]{2}{*}{ Causes of death } & \multicolumn{2}{|c|}{$\begin{array}{l}\text { Full-time exposed } \\
\text { (1324 person-years) }\end{array}$} & \multicolumn{2}{|c|}{$\begin{array}{l}\text { Maintenance workers } \\
\text { (1211 person-years) }\end{array}$} & \multicolumn{2}{|c|}{$\begin{array}{l}\text { Unexposed } \\
\text { (955 person-years) }\end{array}$} \\
\hline & & Observed & Expected & Observed & Expected & Observed & Expected \\
\hline \multirow{6}{*}{$\begin{array}{l}140-209 \\
151 \\
204-207 \\
390-458\end{array}$} & Tumours, total & $9 * *$ & 3.4 & 3 & 3.4 & 1 & $2 \cdot 0$ \\
\hline & stomach & $3 * *$ & $0 \cdot 4$ & 1 & 0.4 & - & - \\
\hline & leukaemia & $2 * *$ & $0 \cdot 14$ & 1 & 0.13 & - & - \\
\hline & Circulatory system & $12 *$ & $6 \cdot 3$ & 8 & 6.6 & 6 & 3.5 \\
\hline & Other causes & 2 & $3 \cdot 8$ & 3 & $3 \cdot 5$ & 3 & $\mathbf{2 \cdot 8}$ \\
\hline & Total & $23 *$ & $13 \cdot 5$ & 14 & $13 \cdot 5$ & 10 & $8 \cdot 3$ \\
\hline
\end{tabular}

${ }^{*} P<0.05 ;{ }^{*} P<0.01$

concentration of $10-50 \mathrm{mg} / \mathrm{m}^{3}$ could be estimated although peaks above the odour threshold still occurred. Ethylene oxide production ceased in 1963 , but ethylene oxide was still used in manufacturing various products.

The following period is characterised by a continuous decrease of exposure; random samples in the 1970 s show a range of $1-10 \mathrm{mg} / \mathrm{m}^{3}$ for ethylene oxide with occasional higher values. Propylene oxide production (according to the chlorohydrin method) replaced the earlier ethylene oxide production in 1964 , and exposure to propylene oxide has been in the range of $10-25 \mathrm{mg} / \mathrm{m}^{3}$, occasionally $120-150$ $\mathrm{mg} / \mathrm{m}^{3}$.

\section{Results}

Tables 1 and 2 show the observed and expected number of deaths from different causes. The calculation of $P$ values is based on the Poisson distribution.

The full-time exposed cohort shows a considerable excess mortality compared with the expected number based on national statistics (Table 1). The excess mortality is of the same magnitude in a restricted subcohort of those with 10 or more years' employ- ment in ethylene oxide production and 20 years' induction-latency time (Table 2).

The excess mortality arises mainly from increased mortality from tumours but also from diseases of the circulatory system. The unexposed cohort, as well as the maintenance cohort, show a mortality pattern which is in fairly good agreement with that expected (Tables 1 and 2) and there are no statistically significant differences between any observed and expected numbers of those cohorts.

The excess mortality from tumours in the fulltime exposed cohort arises from an excess of stomach cancer and leukaemia. The maintenance group showed no overall excess cancer mortality, but the tumours that occurred in this group were restricted to the oesophagus, the stomach and the lymphatic system. Of 16 tumours in deceased or surviving workers in these two cohorts, with more or less heavy exposure for at least one year, there were three cases of leukaemia, six of tumours in the alimentary tract and four of urogenital malignancy (Tables 3 and 4).

A few more malignancies were found, using the Cancer Registry, in surviving subjects (Table 4) but naturally the expected number also increases. With the same premises as in Table 1 , the expected

Table 2 Observed and expected number of deaths from various causes during 1961-77 in three different cohorts, with or without relation to ethylene oxide production. Ten years' exposure/employment and 20 years' induction-latency time or more were required

\begin{tabular}{|c|c|c|c|c|c|c|}
\hline \multirow[t]{2}{*}{ Causes of death } & \multicolumn{2}{|c|}{$\begin{array}{l}\text { Full-time exposed } \\
\text { ( } 372 \text { person-years) }\end{array}$} & \multicolumn{2}{|c|}{$\begin{array}{l}\text { Maintenance workers } \\
\text { ( } 736 \text { person-years) }\end{array}$} & \multicolumn{2}{|c|}{$\begin{array}{l}\text { Unexposed } \\
\text { (603 person-years) }\end{array}$} \\
\hline & Observed & Expected & Observed & Expected & Observed & Expected \\
\hline Tumours, total & $5 * *$ & $1 \cdot 1$ & 3 & $2 \cdot 6$ & 1 & 1.6 \\
\hline stomach & 1 & 0.13 & 1 & $0 \cdot 3$ & - & - \\
\hline leukaemia & $1^{*}$ & 0.04 & i & $0 \cdot 1$ & - & - \\
\hline Circulatory system & $7 * *$ & $2 \cdot 2$ & 6 & $5 \cdot 4$ & 6 & $3 \cdot 2$ \\
\hline Other causes & 1 & $1 \cdot 3$ & 2 & $2 \cdot 8$ & 3 & $2 \cdot 0$ \\
\hline Total & $13 * * *$ & $4 \cdot 6$ & 11 & $10 \cdot 8$ & 10 & $6 \cdot 8$ \\
\hline
\end{tabular}

${ }^{*} \mathrm{P}<0.05 ;{ }^{* *} \mathrm{P}<0.01 ;{ }^{* * *} \mathrm{P}<0.001$ 
Table 3 Description of the tumours that occurred in the three cohorts according to Tables 1 and 2

\begin{tabular}{|c|c|c|c|c|c|}
\hline ICD no. & Site/type & $\begin{array}{l}\text { Full-time exposed } \\
(\geqslant 10 \mathrm{yr})\end{array}$ & $(>1<10 y r)$ & Maintenance workers & Unexposed \\
\hline $\begin{array}{l}150 \\
151 \\
153 \\
172 \\
185 \\
189 \\
204 \\
207\end{array}$ & $\begin{array}{l}\text { Oesophagus } \\
\text { Stomach } \\
\text { Colon } \\
\text { Malignant melanoma } \\
\text { Prostate } \\
\text { Kidney } \\
\text { Chronic lymphatic leukaemia } \\
\text { Acute myeloid leukaemia }\end{array}$ & $\begin{array}{l}1 \\
1 \\
1 \\
1 \\
1\end{array}$ & $\begin{array}{l}2 \\
1\end{array}$ & 1 & 1 \\
\hline \multicolumn{2}{|c|}{$\begin{array}{l}\text { Total number of malignancies in deceased subjects } \\
\text { Cohort code }\end{array}$} & S $+D$ & 4 & $\begin{array}{l}3 \\
\mathbf{B}\end{array}$ & $\mathbf{1}$ \\
\hline
\end{tabular}

total number of malignancies in the full-time exposed cohort would have been 5.9 and 11 malignancies were observed $(P<0.05)$.

In the full-time exposed cohort there were nine deaths due to coronary heart disease (CHD) and three deaths from cerebrovascular disease (CVD). In the unexposed cohort there were four deaths from CHD and two from CVD. In the maintenance group there were six deaths from CHD, one from mitral valvular disease, and one aneurysm of the internal carotid artery.

\section{Discussion}

The majority of the exposed persons were employed before 1950 and were thus exposed to several chemicals. Ethylene dichloride has recently been reported as a carcinogen (National Institute for Occupational Safety and Health, 1978) and ethylene chlorohydrin causes mutation in barley and in several strains of bacteria (Environmental Protection Agency, 1978). Ethylene may be metabolised through epoxidation processes (Ehrenberg et al., 1977). Furthermore, small amounts of other carcinogens, such as bis(2-chloroethyl) ether and chloroform, have been detected in the factory. Thus the excess of malignancies cannot be linked to any particular chemical associated with ethylene oxide production but, considering the amounts of exposure and the toxicological data previously mentioned, it seems reasonable to suspect ethylene oxide and ethylene dichloride, possibly together with ethylene chlorohydrin or ethylene, as causative agents.
The degree of alkylation of haemoglobin amino acids may be used for monitoring the tissue dose of ethylene oxide in exposed subjects (Calleman et al., 1978). From the tissue dose, defined as the time integral of free alkylating agent in cells of the blood or other organs, the risk may then be estimated using the mutagenic action of ionising radiation as a standard (Calleman et al., 1978). Assuming that ethylene oxide is the chief causative agent, and using this mode of calculation, the observed increase in cancer incidence and mortality in the full-time exposed group is compatible with an average concentration of ethylene oxide of the order of $5-55 \mathrm{mg} / \mathrm{m}^{3}$.

Taking into consideration the radiomimetic character of ethylene oxide and its rapid distribution to all organs of the body (Ehrenberg et al., 1974) it seems reasonable to expect the same types of malignancy that arise from ionising radiation, such as leukaemia. A report on leukaemia associated with exposure to ethylene oxide has been mentioned above (Hogstedt et al., 1979). The possibility that the incidence of chronic lymphatic leukaemia, which does not seem to be initiated by acute irradiation, could be increased by repeated exposure to $x$-rays or ethylene oxide, has been discussed by Calleman et al. (1978).

Stomach cancer was reported to be overrepresented among chemical industry operators in an American study (Viadana et al., 1976) and may merit further attention in relation to occupation. However, at present it is difficult to suggest the mechanism of initiation.

Table 4 Additional malignancies found through the Cancer Registry 1961-77 among survivors

\begin{tabular}{|c|c|c|c|c|c|}
\hline ICD no. & Site/type & $\begin{array}{l}\text { Full-time exposed } \\
(\geqslant 10 \mathrm{yr})\end{array}$ & ${ }^{d}(>1<10 \mathrm{yr})$ & Maintenance workers & Unexposed \\
\hline $\begin{array}{l}161 \\
185 \\
186 \\
188 \\
193\end{array}$ & $\begin{array}{l}\text { Glottis } \\
\text { Prostate } \\
\text { Testis } \\
\text { Urinary bladder } \\
\text { Thyroid }\end{array}$ & 1 & 1 & $\begin{array}{l}1 \\
1\end{array}$ & 1 \\
\hline
\end{tabular}


The expected number of lung cancers in the three cohorts with more than one year of exposure and at least ten years' induction-latency time was $2 \cdot 1$ $(0.8$ in the full-time exposed cohort) but no case was found in the Cancer Registry. Smoking habits are not believed, therefore, to have been higher than the national average. The expected number is influenced by the comparatively high frequency of lung cancer in the larger Swedish cities, whereas the population studied lived in a medium-sized Swedish town.

A considerable excess mortality appears also in the diseases of the circulatory system among those with full-time exposure, and there is a similar tendency in the other cohorts. Locally occurring risk factors for such diseases or a local bias in favour of the diagnoses may be suspected but cannot be substantiated. However, it seems doubtful that such factors could fully explain the increased mortality from diseases of the circulatory system, especially when this is considerable, as in the cohort with full-time exposure.

Of some interest in this context is the increased mortality from diseases of the circulatory system, that appeared in the evaluation of causes of deaths among the Swedish vinyl chloride workers (Byrén et al., 1976). In several reports, Benditt has suggested that atherosclerosis could result from mutation initiated by chemical agents (Benditt, 1976). High blood pressure has been associated with increased risk of cancer mortality (Dyer et al., 1975) as well as with increased DNA repair stimulation due to more damaged DNA sites (Nordén et al., 1975). It could be speculated, therefore, that tumours and cardiocerebrovascular morbidity to some extent could have common aetiological factors.

Further studies of the exposed population, as well as a longer follow-up of those exposed in $\mathbf{1 9 5 0}$ and later, might more fully elucidate the risk from ethylene oxide manufacture. Furthermore, it seems important to evaluate other groups with exposure to ethylene oxide as this compound is extensively used in the chemical industry, in medical settings and elsewhere.

\section{References}

Benditt, E. P. (1976). Implications of the monoclonal character of human atherosclerotic plaques. Beiträge zur Pathologie, 158, 405-416.

Byrén, D., Engholm, G., Englund, A., and Westerholm, P. (1976). Mortality and cancer morbidity in a group of
Swedish VCM and PVC production workers. Environmental Health Perspectives, 17, 167-170.

Calleman, C. J., Ehrenberg, L., Jansson, B., OstermanGolkar, S., Segerbäck, D., Svensson, K., and Wachtmeister, C. A. (1978). Monitoring and risk assessment by haemoglobin alkylation in persons occupationally exposed to ethylene oxide. Journal of Environmental Pathology and Toxicology, 2, 427-442.

Dyer, A. R., Stamler, J., Berkson, D. M., Lindberg, H. A., and Stevens, E. (1975). High blood-pressure: a risk factor for cancer mortality. Lancet, 1, 1051-1056.

Ehrenberg, L., and Gustafsson, A. (1970). Chemical Mutagens: Their Uses and Hazards in Medicine and Technology. Report to the National Board of Health, February 1959, pp. 10-12. Institute of Genetics: Lund, Sweden.

Ehrenberg, L., Hiesche, K. D., Osterman-Golkar, S., and Wennberg, I. (1974). Evaluation of genetic risks of alkylating agents: tissue doses in the mouse from air contaminated with ethylene oxide. Mutation Research, 24, 83-103.

Ehrenberg, L., and Hällström, T., cited by L. O. Kalling. (1967). Haematologic studies on persons occupationally exposed to ethylene oxide. In Radiosterilization of Medical Products, pp. 327-334. International Atomic Energy Agency SM 92/96. IAEA: Vienna.

Ehrenberg, L., Osterman-Golkar, S., Segerbäck, D., Svensson, K., and Calleman, C. J. (1977). Evaluation of genetic risks of alkylating agents. III. Alkylation of haemoglobin after metabolic conversion of ethene to ethene oxide in vivo. Mutation Research, 45, 175-184.

Environmental Protection Agency (1978). Ethylene oxide. Federal Register, 43, 3799-3815.

Hine, C. H., and Rowe, V. (1963). Ethylene oxide. In Industrial Hygiene and Toxicology, pp. 1626-1634. Edited by F. A. Patty. Interscience Publishers: New York.

Hogstedt, C., Malmqvist, N., and Wadman, B. (1979). Leukemia in workers exposed to ethylene oxide. Journal of the American Medical Association, 241, 1132-1133.

International Agency for Research on Cancer (1976). Monographs on the Evaluation of Carcinogenic Risk of Chemicals to Man, Vol. 11, pp. 161-163. IARC: Lyon. Joyner, R. E. (1964). Chronic toxicity of ethylene oxide. Archives of Environmental Health, 8, 700-710.

National Institute for Occupational Safety and Health (1977). Use of Ethylene Oxide as a Sterilant in Medical Facilities. Special Occupational Hazard Review. USPHS: Rockville.

National Institute for Occupational Safety and Health (1978). Ethylene Dichloride. Current Intelligence Bulletin No. 25. USPHS: Rockville.

Nordén, Å., Scherstén, B., Thulin, T., Pero, R. W., Bryngelsson, C., and Mittelman, F. (1975). Hypertension related to DNA repair synthesis and carcinogen uptake. Lancet, 2, 1094.

Rapoport, I. A. (1948). Dejstvie okisi etilena, glitsida i glikolej na gennye mutatsii. Doklady Akademii Nauk $S S S R, 60,469-472$.

Van Duuren, B. L., Orris, L., and Nelson, N. (1965). Carcinogenicity of epoxides, lactones, and peroxy compounds. II. Journal of the National Cancer Institute, 35, 707-717.

Viadana, E., Bross, I. D. J., and Houten, L. (1976). Cancer experience of men exposed to inhalation of chemicals or to combustion products. Journal of Occupational Medicine, 18, 787-792.

Walpole, A. L. (1957). Carcinogenic action of alkylating agents. Annals of the New York Academy of Sciences, 68, 750-761. 